\title{
PROGRESSO DA BRUSONE NAS FOLHAS E CARACTERÍSTICAS AGRONÔMICAS NAS GERAÇÕES AVANÇADAS DE SOMACLONES AROMÁTICOS DA CULTIVAR DE ARROZ IAC 47
}

\author{
LEILA G. ARAÚJO \& ANNE S. PRABHU \\ Embrapa Arroz e Feijão, Cx. Postal 179, CEP 75375-000, Santo Antônio de Goiás, GO, fax: (062) 833-2100, \\ e-mail: leilag@cnpaf.embrapa.br, prabhu@cnpaf.embrapa.br
}

(Aceito para publicação em 15/05/2001)

Autor para correspondência: Leila G. Araújo

ARAÚJO, L.G. \& PRABHU, A.S. Progresso da brusone nas folhas e características agronômicas nas gerações avançadas de somaclones aromáticos da cultivar de arroz IAC 47. Fitopatologia Brasileira 26:606-613. 2001

\section{RESUMO}

Foram conduzidos experimentos de campo por três anos utilizando somaclones da cultivar de arroz (Oriza sativa) de terras altas IAC 47. A variação para resistência à brusone e para outras características agronômicas foram avaliadas nas gerações avançadas de $R_{5}, R_{6}$ e $R_{7}$. $O$ progresso lento da brusone foi medido baseado na área sob a curva de progresso de doença (ASCPD) e taxa aparente de infecção $(r)$. As correlações nas gerações $\mathrm{R}_{6}$ e $\mathrm{R}_{7}$ em relação a ASCPD e $r$ foram positivas e altamente significantes. Os somaclones também mostraram dois tipos distintos de plantas, um com folha ereta verde escura e outro com folha decumbente verdeamarela, arquiteturas diferentes do tipo de planta da cultivar IAC 47, a qual é caracterizada por folha decumbente verde- palha. Todos os somaclones exibiram característica aromática do grão. Os somaclones mostraram também variação para tipo de grão, altura, duração do ciclo, peso de grãos de 100 panículas e produtividade. Foram identificados dois somaclones SCIA02 e SCIA06 que mostraram progresso lento de doença, precocidade e alto potencial de produtividade, comparados à cultivar parental IAC 47, além de possuir característica aromática e tipo de planta com folha ereta verdeescura. Estes somaclones podem ser utilizados como novas fontes de resistência à brusone no melhoramento de arroz de sequeiro.

Palavras-chave: cultura de tecidos, epidemiologia, Oryza sativa, Pyricularia grisea.

\section{ABSTRACT \\ Progress of leaf blast and other agronomic characteristics in advanced generations of aromatic somaclones of rice cultivar IAC 47}

Field trials were conducted over three seasons with somaclones derived from the upland rice (Oriza sativa) cultivar IAC 47. Variation for rice blast resistance and other agronomic traits were assessed in the advanced generations of $\mathrm{R}_{5}, \mathrm{R}_{6}$, and $\mathrm{R}_{7}$. The slow blasting resistance was evaluated based on the area under disease progress curve (AUDPC) and apparent infection rate $(r)$. The correlations between $\mathrm{R}_{6}$ and $\mathrm{R}_{7}$ generations in relation to AUDPC as well as $r$ were positive and highly significant. Somaclones also showed two distinct plant types, one with erect bright green leaves and other with droopy yellow green leaves different from the plant type of cultivar IAC 47 which is characterized by droopy pale green leaves. All somaclones exhibited aromatic grain characteristic. Somaclones also showed variation in grain type, height, growth duration, panicle grain weight and grain yield. Two somaclones SCIA02 and SCIA06 were identified that showed slow blasting resistance, early growth duration, and high yield potential compared to the parent cultivar IAC 47 besides the aromatic grain characteristic and plant type with erect bright green leaves. They can be used as new blast resistant sources for upland rice improvement.

\section{INTRODUÇÃO}

A brusone, cujo agente causal é o fungo Pyricularia grisea (Cook) Sacc., constitui-se em uma das doenças mais destrutivas em arroz (Oriza sativa L.) de terras altas no Brasil. A brusone nas folhas durante a fase vegetativa causa redução na estatura da planta, no número de perfilhos, no número de grãos por panícula e no peso de grãos, além dos efeitos indiretos na produtividade causados pela redução na taxa de fotossíntese e respiração (Bastiaans et al., 1994).

O principal componente no manejo da brusone é a resistência genética, para alcançar os objetivos de uma agricultura sustentável e evitar a dependência de produtos químicos no seu controle. A cultivar IAC 47 foi a mais plantada no Brasil desde seu lançamento em 1973, devido a sua tolerância à deficiência hídrica e adaptação às condições 
Progresso da brusone nas folhas e características agronômicas nas gerações...

de solo de cerrado. Um dos fatores limitantes a sua produtividade foi a alta suscetibilidade à brusone, necessitando melhoramento para incorporação da resistência à $P$. grisea. Os métodos convencionais através de cruzamentos desta cultivar com doadores de resistência à $P$. grisea, normalmente de arroz irrigado, resultam na maioria dos casos, em características não desejáveis como mancha de grãos (Prabhu \& Ferreira, 1989).

A variação somaclonal foi proposta como método de aumentar a variação genética para resistência às doenças e outras características agronômicas no melhoramento das cultivares adaptadas às condições locais (Duval et al., 1998). Algumas características morfológicas e agronômicas como coloração da arista do grão e apículo, altura, perfilhamento, tipo de planta, floração, peso de grãos e rendimento, obtidas por variação somaclonal, demonstraram ser herdáveis em arroz. A maioria das características são controladas por um ou poucos genes (Mandal \& Bandyopadhyay, 1996). Muitas características quantitativas como tolerância à salinidade, toxidez de alumínio e tolerância à herbicida têm base celular (Mandal et al., 1999).

Somaclones com diferentes graus de resistência à brusone foram obtidos a partir de cultivares suscetíveis de arroz (Chauhan et al., 1996). No Brasil foram obtidos somaclones da cultivar de arroz Araguaia com resistência vertical e parcial à brusone e planta tipo leque (Araújo et al., 2000). Foram obtidos, também, resultados promissores com o desenvolvimento de somaclones da cultivar de arroz IAC 47 que apresentaram diversos graus de resistência parcial à brusone nas gerações iniciais (Araújo et al., 1997). Entretanto, em alguns casos, as características desejáveis não expressam estabilidade nas gerações subseqüentes e, freqüentemente, a maioria dos variantes fenotípicos são deletérios (Zheng et al., 1989).

O presente trabalho objetivou estudar o grau de resistência à brusone e algumas características agronômicas nas gerações avançadas de somaclones da cultivar de arroz IAC 47.

\section{MATERIAL E MÉTODOS}

O procedimento de desenvolvimento de somaclones consistiu na indução de calos e regeneração de plantas a partir de panículas imaturas da cultivar de arroz IAC 47, seleção de plantas resistentes nas gerações $\mathrm{R}_{2}$ e $\mathrm{R}_{3}$, avanço da geração $\mathrm{R}_{4}$, reavaliação da resistência à brusone e de outras características agronômicas nas gerações $R_{5}, R_{6}$ e $R_{7}$. A nomenclatura proposta por Yurkova et al. (1982) foi utilizada, sendo $R_{1}$ regenerante primário, $R_{2}, R_{3}, R_{4}, R_{5}$ e $R_{6}$, a primeira, segunda, terceira, quarta e quinta progênies autofecundadas.

A geração $R_{4}$ foi avançada através da multiplicação das sementes coletadas de plantas individuais da geração $R_{3}$. As sementes provenientes de cada planta foram semeadas em uma linha de $2 \mathrm{~m}$, em Junho de 1995 e irrigadas por inundação. Procedeu-se a colheita massal de 20 plantas $\mathrm{R}_{4}$ de cada somaclone, totalizando 41 somaclones.
Na geração $R_{5}$ foi realizado um experimento de campo em condições de terras altas na safra 1995/96 com 17 somaclones e a cultivar IAC 47, em um latossolo VermelhoAmarelo Distrófico. O delineamento experimental foi o de blocos completos casualizados com três repetições. O solo foi adubado com $300 \mathrm{~kg} / \mathrm{ha}$ da fórmula 4-30-16, $25 \mathrm{~kg} / \mathrm{ha}$ de $\mathrm{N}$, na forma de sulfato de amônio e $5 \mathrm{~kg} / \mathrm{ha}$ de $\mathrm{Zn}$, na forma de sulfato de zinco, no sulco, por ocasião do plantio. Utilizou-se o espaçamento de 0,3 m e uma densidade de semeadura de 80 sementes $/ \mathrm{m}$. Cada parcela constituiu-se de cinco linhas de $4 \mathrm{~m}$, com área total de $6 \mathrm{~m}^{2}$. Trinta dias antes do plantio do experimento, uma bordadura com três linhas de uma mistura das cultivares suscetíveis IAC 47, IAC 25, IAC 165 e IRAT 112 em proporções iguais, foi semeada perpendicular às linhas das parcelas. A brusone nas folhas foi avaliada com base no número de lesões esporulativas por folha e severidade. Para a determinação do número de lesões esporulativas foram utilizados os perfilhos principais de dez plantas tomados ao acaso em três linhas centrais, 40 dias após o plantio. A severidade, expressa em porcentagem de área foliar afetada, foi determinada em três folhas superiores completamente abertas, dos perfilhos principais de dez plantas, em três linhas centrais da parcela, 49 dias após o plantio. Utilizou-se uma escala de dez graus $(0 ; 0,5 ; 1,0 ; 2,0 ; 4,0 ; 8,0 ; 16,0 ; 32,0$; 64,$0 ; 82,0 \%$ de área foliar afetada) de acordo com Notteghem (1981). A severidade da brusone, também foi avaliada em 100 panículas, em três linhas centrais, dez dias antes da colheita, utilizando uma escala de cinco graus $(0,5,25,50$, 75 e $100 \%$ de espiguetas infetadas por panícula). Avaliou-se também o peso dos grãos de 100 panículas coletadas nas três linhas centrais. A semente $R_{5}$ dos demais somaclones foi multiplicada em vasos, em casa de vegetação.

Em $\mathrm{R}_{6}$ foram realizados dois experimentos de campo, um deles com 41 somaclones e o outro com 17, na safra 1996/ 97. No primeiro foi utilizado o delineamento de blocos ao acaso com três repetições e as parcelas consistiram de uma linha de $2 \mathrm{~m}$, espaçadas de $0,35 \mathrm{~m}$. A adubação foi a mesma usada para geração $\mathrm{R}_{5}$. Avaliou-se a incidência da brusone nas folhas em cinco plantas de cada parcela tomadas ao acaso, 30 dias após o plantio. A incidência, em porcentagem, foi calculada com base na relação entre o número de folhas infetadas e o total de folhas. Para análise de variância os dados da incidência foram transformados em $\operatorname{arcoseno} \sqrt{\mathrm{x}}$ onde $\mathrm{x}$ é a porcentagem de folhas infetadas. Avaliou-se também a severidade da brusone nas folhas utilizando a mesma escala da geração $R_{5}$. Foram realizadas seis observações seriais em intervalos de três a quatro dias para se plotar a curva de progresso de doença. A área sob a curva de progresso da doença (ASCPD) nas folhas foi calculada para cada genótipo de acordo com Shaner \& Finney (1977). Para a análise de variância os dados de ASCPD foram transformados utilizando $\log _{10}$. A taxa de aumento da brusone com o tempo, ou taxa aparente de infecçãom $(r)$, foi calculada pelo método de regressão linear, após a transformação das proporções da brusone para $\log _{\mathrm{e}}[\mathrm{y} /(1-\mathrm{y})]$, segundo Vanderplank (1963). O coeficiente de determinação foi usado para testar a 
significância das regressões lineares. As significâncias de $r$ de cada somaclone e da cultivar IAC 47 foram testadas através do teste $t$, de acordo com Snedecor \& Cochran (1978). Foi feita a análise de regressão e correlação entre a incidência, $r$ e ASCPD. Foram avaliadas também algumas características agronômicas, incluindo a altura da planta, o comprimento da panícula, a porcentagem de grãos cheios, o tipo de planta, a duração do ciclo, o tipo de grão e o aroma. A altura foi medida em uma planta ao acaso. O comprimento da panícula e a porcentagem de grãos cheios foram baseados em uma amostra ao acaso de três panículas. O potencial de produção dos somaclones foi medido com base no peso de grãos de 100 panículas. Foi realizada a análise de variância para altura, comprimento da panícula, porcentagem de grãos cheios e peso de grãos de 100 panículas. O tipo de grão foi avaliado com base em uma escala de quatro graus $\left(\mathrm{T}_{0}=\right.$ grão igual a cultivar IAC 47, com apículo preto e sem arista; $\mathrm{T}_{1}=$ grão com arista vermelha; $\mathrm{T}_{2}=$ grão com apículo branco e sem arista; $\mathrm{T}_{3}=$ grão com arista preta). O teste do aroma foi realizado no emborrachamento utilizando $2 \mathrm{~g}$ da penúltima folha. $\mathrm{O}$ método consiste na imersão de $2 \mathrm{~g}$ de folha picada em $10 \mathrm{ml}$ de solução de $\mathrm{KOH}$ a $1,7 \%$ em tubos de ensaio por $10 \mathrm{~min}$ a uma temperatura de $30^{\circ} \mathrm{C}$ (Sood \& Siddiq, 1978). Os somaclones foram classificados como aromáticos com base no aroma emitido no tubo, através do cheiro.

No segundo experimento da geração $\mathrm{R}_{6}$ foi utilizado o delineamento de blocos completos cazualizados com três repetições e as parcelas consistiram de cinco linhas de $4 \mathrm{~m}$ espaçadas de $0,35 \mathrm{~m}$. Foram avaliados o número de grãos totais por panícula, degranação, severidade da brusone nas panículas e produtividade. O número de grãos totais foi medido em uma amostra de oito panículas. Para a leitura de degranação utilizou-se cinco panículas e fez-se a leitura com base em uma escala de três graus $(1=$ poucos grãos removidos das panículas; $2=25-50 \%$ de grãos removidos e $3=$ mais que $50 \%$ de grãos removidos). A produtividade, ajustada para $13 \%$ de umidade, baseou-se na área útil de 2,62 $\mathrm{m}^{2}$.

$\mathrm{Na}$ geração $\mathrm{R}_{7}$ realizaram-se dois experimentos de campo, um com 41 somaclones e outro com 17 na safra 1997/ 98. No primeiro utilizou-se o mesmo delineamento experimental e adubação da geração $\mathrm{R}_{6}$, mas as parcelas consistiram de quatro linhas de $2 \mathrm{~m}$, espaçadas de $0,35 \mathrm{~m}$. A ASCPD e $r$ foram avaliadas da mesma maneira que em $R_{6}$. Fez-se a análise de regressão e correlação dos valores de ASCPD entre somaclones das gerações $\mathrm{R}_{6}$ e $\mathrm{R}_{7}$, bem como de $\mathrm{r}$. Avaliou-se também o tipo de planta, duração do ciclo, tipo de grão e aroma. O segundo experimento de campo foi semelhante ao realizado em $\mathrm{R}_{7}$, mas a parcela consistiu de quatro linhas de $5 \mathrm{~m}$ de comprimento. Avaliou-se o peso de grãos de 100 panículas e a produtividade em uma área útil de $3,2 \mathrm{~m}^{2}$.

\section{RESULTADOS E DISCUSSÃO}

As diferenças entre os somaclones em relação ao número de lesões por folha e a severidade na fase vegetativa foram significativas (Tabela 1). Dos 17 somaclones avaliados,
SCIA14, SCIA01 e SCIA02 diferiram significativamente da cultivar IAC 47. Somente SCIA14 diferiu significativamente da cultivar IAC 47 quanto à brusone nas panículas. Os somaclones SCIA14, SCIA01 e SCIA02, que apresentaram maior grau de resistência à brusone nas folhas, não diferiram da cultivar IAC 47 quanto ao peso de grãos de 100 panículas (Tabela 1). Estes resultados indicaram variação entre os somaclones para resistência à brusone e peso de grãos de 100 panículas nas linhas $R_{5}$ homozigotas (Tabela 1). Com base nestes resultados o trabalho foi ampliado utilizando 41 somaclones $\mathrm{R}_{5}$ multiplicados e colhidos em casa de vegetação para os estudos subseqüentes.

A incidência da brusone nas folhas, expressa pela porcentagem de folhas com lesões esporulativas, variou de 17,7 a 57,8\% entre os somaclones, não diferindo da cultivar IAC 47. Considerando a área sob a curva de progresso dos somaclones $\mathrm{R}_{6}$, sete apresentaram valores significativamente menores do que a cultivar IAC 47. Entre 41 somaclones, $21 \mathrm{e}$ seis apresentaram valores de $r$ menores e maiores em relação à cultivar IAC 47, respectivamente (Tabela 2). A relação entre incidência e ASCPD não foi linear, pois a ASCPD aumentou de maneira logarítmica com o aumento da porcentagem da incidência da brusone nas folhas (Figura 1A). Entretanto, a relação entre $r$ e ASCPD foi linear e positiva (Figura 1B), sendo a correlação significativa $\left(\mathrm{R}^{2}=0,96\right)$. Segundo o progresso da brusone nas folhas nos somaclones SCIA06 e SCIA02 e na cultivar IAC 47 (Figura 2), os valores de $r$ dos somaclones SCIA02 $(0,005)$ e SCIA06 $(0,0016)$ foram menores que o da cultivar IAC $47(0,013)$ indicando progresso lento da brusone nas condições de campo na geração $\mathrm{R}_{6}$.

O termo progresso lento da brusone foi utilizado como

TABELA 1 - Número de lesões por folha, severidade de brusone nas folhas, incidência de brusone nas panículas, peso de grãos de 100 panículas de 17 somaclones $R_{5}$ da cultivar de arroz (Oriza sativa) IAC 47 (1995/96)

\begin{tabular}{ccccc}
\hline \hline Genótipo & $\begin{array}{c}\text { Número de } \\
\text { lesões/folha }\end{array}$ & Severidade & $\begin{array}{c}\text { Incidência em } \\
\text { panículas }(\%)\end{array}$ & $\begin{array}{c}\text { Peso de grãos de } \\
\mathbf{1 0 0} \text { panículas (g) }\end{array}$ \\
\hline${\text { IAC } 47^{1}}^{1}$ & $24,11 \mathrm{a}^{3}$ & $60,72 \mathrm{a}$ & $72,93 \mathrm{a}$ & $49,14 \mathrm{ab}$ \\
SCIA $^{2} 03$ & $12,28 \mathrm{ab}$ & $30,38 \mathrm{ab}$ & $38,83 \mathrm{ab}$ & $31,86 \mathrm{~b}$ \\
SCIA09 & $11,10 \mathrm{ab}$ & $17,30 \mathrm{ab}$ & $53,47 \mathrm{ab}$ & $27,85 \mathrm{~b}$ \\
SCIA08 & $8,83 \mathrm{ab}$ & $41,93 \mathrm{ab}$ & $28,47 \mathrm{ab}$ & $37,96 \mathrm{~b}$ \\
SCIA 11 & $6,70 \mathrm{ab}$ & $13,43 \mathrm{ab}$ & $56,37 \mathrm{ab}$ & $41,99 \mathrm{ab}$ \\
SCIA 15 & $5,26 \mathrm{ab}$ & $25,33 \mathrm{ab}$ & $43,53 \mathrm{ab}$ & $37,46 \mathrm{~b}$ \\
SCIA13 & $4,73 \mathrm{ab}$ & $5,40 \mathrm{ab}$ & $59,13 \mathrm{ab}$ & $74,76 \mathrm{a}$ \\
SCIA07 & $4,73 \mathrm{ab}$ & $8,30 \mathrm{ab}$ & $47,77 \mathrm{ab}$ & $30,93 \mathrm{~b}$ \\
SCIA 10 & $4,10 \mathrm{ab}$ & $11,40 \mathrm{ab}$ & $58,10 \mathrm{ab}$ & $27,35 \mathrm{~b}$ \\
SCIA 17 & $4,03 \mathrm{ab}$ & $6,03 \mathrm{ab}$ & $28,57 \mathrm{ab}$ & $32,96 \mathrm{ab}$ \\
SCIA 12 & $3,86 \mathrm{ab}$ & $6,70 \mathrm{ab}$ & $12,63 \mathrm{ab}$ & $57,73 \mathrm{ab}$ \\
SCIA 16 & $3,26 \mathrm{ab}$ & $3,57 \mathrm{~b}$ & $58,43 \mathrm{ab}$ & $64,51 \mathrm{ab}$ \\
SCIA04 & $2,77 \mathrm{ab}$ & $4,53 \mathrm{ab}$ & $17,93 \mathrm{ab}$ & $65,13 \mathrm{ab}$ \\
SCIA05 & $2,53 \mathrm{ab}$ & $12,37 \mathrm{ab}$ & $36,33 \mathrm{ab}$ & $29,78 \mathrm{~b}$ \\
SCIA06 & $1,64 \mathrm{~b}$ & $4,70 \mathrm{ab}$ & $45,53 \mathrm{ab}$ & $67,34 \mathrm{ab}$ \\
SCIA 14 & $1,46 \mathrm{~b}$ & $3,37 \mathrm{~b}$ & $3,00 \mathrm{~b}$ & $70,77 \mathrm{ab}$ \\
SCIA01 & $0,93 \mathrm{~b}$ & $2,18 \mathrm{~b}$ & $31,70 \mathrm{ab}$ & $65,00 \mathrm{ab}$ \\
SCIA02 & $0,46 \mathrm{~b}$ & $0,76 \mathrm{~b}$ & $30,50 \mathrm{ab}$ & $94,76 \mathrm{a}$ \\
\hline
\end{tabular}

Testemunha suscetível, não regenerada; ${ }^{2}$ Somaclone de IAC $47 ;{ }^{3}$ Médias seguidas da mesma letra não diferem pelo teste de Tukey a 5\% de probabilidade. 
Progresso da brusone nas folhas e características agronômicas nas gerações...

TABELA 2 - Incidência, área sob a curva de progresso de doença (ASCPD) e taxa aparente de infecção (r) da brusone de 41 somaclones $R_{6}$ e $R_{7}$ da cultivar de arroz (Oryza sativa) IAC 47

\begin{tabular}{|c|c|c|c|c|c|}
\hline \multirow[b]{2}{*}{ Genótipo } & \multicolumn{3}{|c|}{ Geração $R_{6}(1996 / 97)$} & \multicolumn{2}{|c|}{ "Geração $R_{7}(1997 / 98)$} \\
\hline & $\begin{array}{c}\text { Incidência }^{3} \\
(\%)\end{array}$ & $(\mathrm{ASCPD})^{4}$ & $(r)^{5}$ & $(\mathrm{ASCPD})^{4}$ & $(r)^{5}$ \\
\hline SCIA $^{\perp} 01$ & 35,54 & 104,55 & $0,0045^{* *}$ & $6,18^{*}$ & 0,0001 ** \\
\hline SCIA 02 & 19,97 & $45,86^{*}$ & $0,0016 * *$ & $6,49^{*}$ & $0,0001 * *$ \\
\hline SCIA 03 & 31,20 & $67,58 *$ & $0,0035 * *$ & 11,27 & $0,0002 * *$ \\
\hline SCIA 04 & 17,74 & $49,05^{*}$ & $0,0027 * *$ & $7,46 *$ & $0,0001 * *$ \\
\hline SCIA 05 & 31,07 & 108,45 & $0,0041 * *$ & 14,72 & $0,0003 * *$ \\
\hline SCIA 06 & 35,54 & 114,36 & $0,0050 * *$ & 16,64 & $0,0003 * *$ \\
\hline SCIA 07 & 51,07 & 286,48 & 0,0140 & 44,07 & 0,0012 \\
\hline SCIA 08 & 51,07 & 207,02 & 0,0101 & 38,66 & 0,0009 \\
\hline SCIA 09 & 42,21 & 208,07 & $0,0090 *$ & 26,13 & $0,0005^{*}$ \\
\hline SCIA 10 & 53,31 & 283,85 & 0,0158 & 60,40 & 0,0012 \\
\hline SCIA 11 & 46,64 & 217,73 & 0,0111 & 54,27 & 0,0012 \\
\hline SCIA 12 & 39,97 & 79,92 & $0,0033 * *$ & 20,80 & $0,0003^{* *}$ \\
\hline SCIA 13 & 46,64 & 155,52 & $0,0060 * *$ & 34,74 & $0,0005^{*}$ \\
\hline SCIA 14 & 51,77 & 119,13 & 0,0050 & 28,61 & 0,0006 \\
\hline SCIA 15 & 51,21 & 344,20 & $0,0208 * *$ & 59,71 & $0,0019^{*}$ \\
\hline SCIA 16 & 42,11 & 186,42 & 0,0083 & 45,65 & 0,0010 \\
\hline SCIA 17 & 51,07 & 558,07 & $0,0210^{*}$ & $373,07^{*}$ & $0,0129 * *$ \\
\hline SCIA 18 & 26,64 & 100,88 & $0,0043 * *$ & 11,80 & $0,0002 * *$ \\
\hline SCIA 19 & 37,77 & 103,18 & $0,0044 * *$ & 13,66 & $0,0003 * *$ \\
\hline SCIA 20 & 35,54 & $99,13 *$ & $0,0036 * *$ & 25,24 & $0,0004 *$ \\
\hline SCIA 21 & 36,54 & 117,90 & $0,0044 * *$ & $13,47^{*}$ & $0,0001^{* *}$ \\
\hline SCIA 22 & 31,11 & 57,58 & $0,0023 * *$ & 9,03 & $0,0001 * *$ \\
\hline SCIA 23 & 31,07 & 120,48 & $0,0057 * *$ & 8,34 & $0,0001^{* *}$ \\
\hline SCIA 24 & 33,31 & $63,72 *$ & $0,0025 * *$ & 10,29 & $0,0002 * *$ \\
\hline SCIA 25 & 22,17 & $68,86^{*}$ & $0,0035 * *$ & 10,87 & $0,0002 * *$ \\
\hline SCIA 26 & 48,41 & 314,17 & $0,0197 *$ & $274,56^{*}$ & $0,0088^{* *}$ \\
\hline SCIA 27 & 50,97 & 299,17 & 0,0101 & 45,24 & 0,0009 \\
\hline SC IA 28 & 55,54 & 183,68 & $0,0084 *$ & 26,65 & $0,0005^{*}$ \\
\hline SCIA 29 & 48,60 & 328,80 & $0,0197 *$ & 85,59 & 0,0014 \\
\hline SCIA 30 & 26,67 & $76,94^{*}$ & $0,0035^{* *}$ & 20,64 & $0,0003 * *$ \\
\hline SCIA 31 & 48,84 & 96,63 & $0,0035 * *$ & 21,20 & 0,0007 \\
\hline SCIA 32 & 53,31 & 313,48 & 0,0133 & 56,17 & 0,0012 \\
\hline SCIA 33 & 48,87 & 345,30 & $0,0197^{*}$ & 65,14 & $0,0019^{*}$ \\
\hline SCIA 34 & 50,97 & 496,43 & $0,0272 * *$ & 62,64 & 0,0014 \\
\hline SCIA 35 & 46,64 & 142,82 & $0,0051 * *$ & 30,92 & $0,0005^{*}$ \\
\hline SCIA 36 & 57,77 & 417,25 & 0,0134 & 58,64 & 0,0012 \\
\hline SCIA 37 & 51,07 & 240,87 & 0,0096 & 31,82 & 0,0012 \\
\hline SCIA 38 & 51,07 & 227,07 & 0,0094 & 40,58 & 0,0008 \\
\hline SCIA 39 & 46,64 & 197,18 & 0,0106 & 59,29 & 0,0006 \\
\hline SCIA 40 & 51,11 & 314,47 & 0,0094 & 134,99 & 0,0008 \\
\hline SCIA 41 & 53,31 & 284,83 & 0,0133 & 60,11 & 0,0014 \\
\hline IAC $47^{2}$ & 44,41 & 272,67 & 0,0134 & 43,74 & 0,0010 \\
\hline
\end{tabular}

Somaclone de IAC $47 ;{ }^{2}$ Testemunha suscetível, não regenerada; ${ }^{3}$ Nenhum dos somaclones diferiu da cultivar IAC 47 pelo teste de Tukey a 5\% de probabilidade; ${ }^{4}$ Médias seguidas por um asterisco diferem significativamente da cultivar IAC 47 pelo teste de Tukey a $5 \%$ de probabilidade; ${ }^{5}$ Médias seguidas por asteriscos diferem significativamente da cultivar IAC 47 de acordo com o teste $t$ a $5 \%$ (*) e $1 \%(* *)$ de probabilidade.

sinônimo de resistência de campo para descrever a capacidade do arroz em reduzir a velocidade de desenvolvimento da brusone sem nenhuma conotação genética (Ahn, 1981). A taxa aparente de infecção tem sido um parâmetro indicado para comparar as cultivares quanto ao grau de resistência horizontal (Vanderplank, 1963). A taxa varia não somente com a resistência, mas também com o estágio de desenvolvimento da cultivar e localidade (Prabhu \& Bedendo, 1991). Prabhu et al. (1996) ainda mostraram que é necessário utilizar mais que um critério para identificar genótipos caracterizados por progresso lento da brusone. A correlação entre ASCPD e $r$ indica a precisão e consistência dos dados.

A altura foi significativamente menor para SCIA01, SCIA04, SCIA24, SCIA39 e SCIA41 e maior para SCIA17, SCIA19, SCIA25, e SCIA32 comparados à cultivar IAC 47
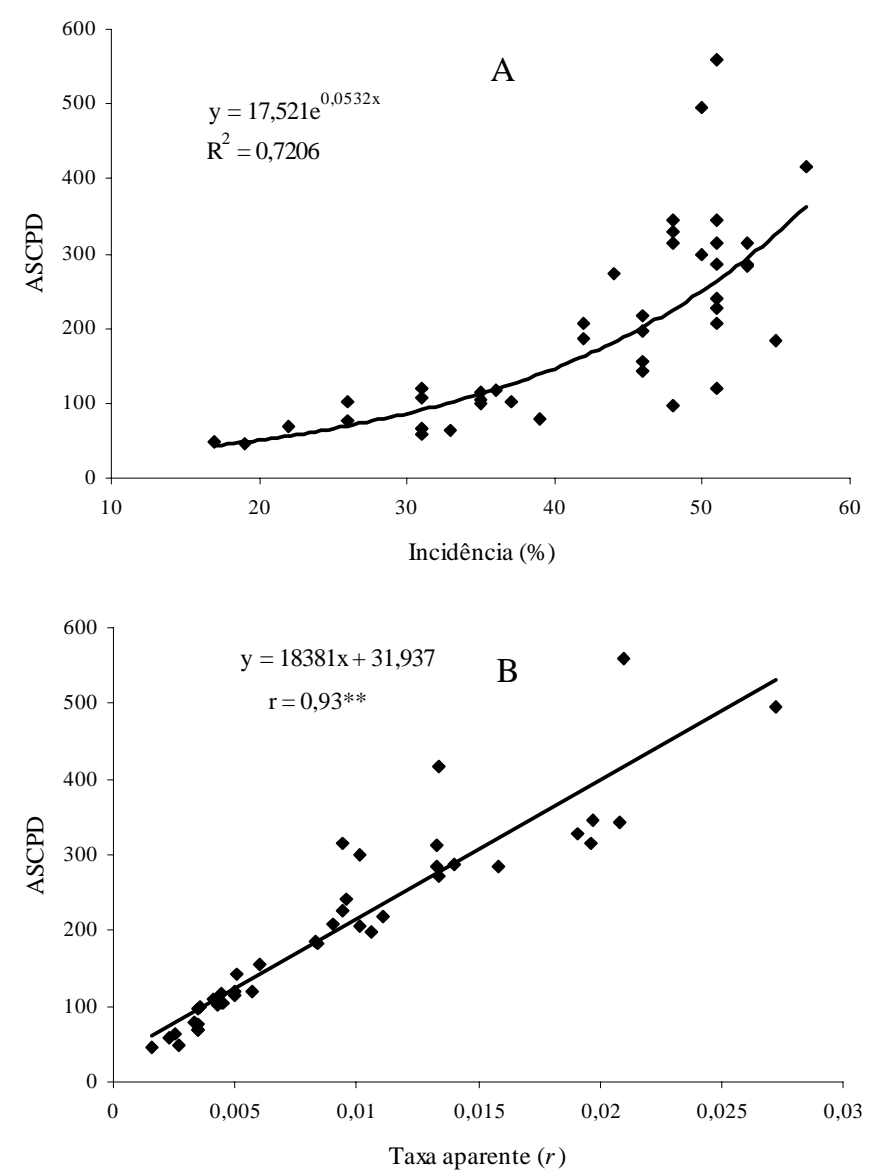

FIG. 1 - Relação entre incidência e área sob a curva de progresso de doença (ASCPD) da brusone nas folhas (A) e entre taxa aparente de infecção $(r)$ e área sob a curva de progresso (B) de 41 somaclones $\mathbf{R}_{6}$ e a cultivar de arroz (Oryza sativa) IAC 47. (Os pontos indicam as médias das observações de cada genótipo).

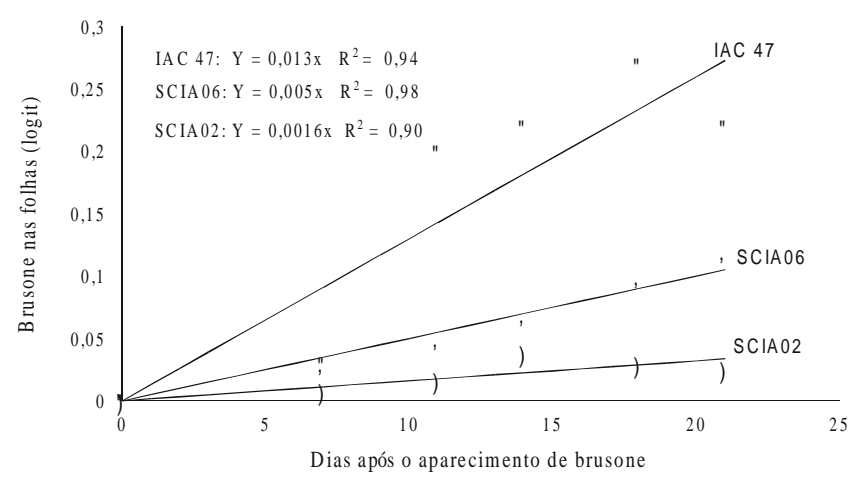

FIG. 2 - Progresso da brusone nas folhas dos somaclones SCIA06 e SCIA02, e da cultivar de arroz (Oryza sativa) IAC 47.

(Tabela 3). Os somaclones não diferiram da cultivar IAC 47 quanto ao comprimento de panícula, porcentagem de grãos 
cheios e peso de grãos por 100 panículas, entretanto, apresentaram dois tipos de plantas distintos, um com folha ereta verdeescura (EVE) e outro com folha decumbente verde-amarelo
(DVA). Os dois tipos de plantas foram diferentes da cultivar IAC 47 que apresentou folha decumbente verde-palha (DVP). Diversos genes marcadores afetando características morfo-

TABELA 3 - Altura, comprimento de panícula, porcentagem de grãos cheios, peso de grãos de 100 panículas, tipo de planta e tipo de grão de 41 somaclones $R_{6} e$ da cultivar de arroz (Oryza sativa) IAC 47 (1996/97)

\begin{tabular}{|c|c|c|c|c|c|c|}
\hline Genótipo & $\begin{array}{c}\text { Altura } \\
(\mathrm{cm})^{5}\end{array}$ & $\begin{array}{l}\text { Comprimento } \\
\text { de panícula } \\
(\mathrm{cm})^{6}\end{array}$ & $\begin{array}{c}\text { Porcentagem } \\
\text { de grãos } \\
\text { cheios }^{6}\end{array}$ & $\begin{array}{c}\text { Peso de grãos de } \\
100 \text { panículas } \\
(\mathrm{g})^{6}\end{array}$ & $\begin{array}{l}\text { Tipo de } \\
\text { planta }\end{array}$ & $\begin{array}{c}\text { Tipo } \\
\text { de grão }\end{array}$ \\
\hline $\operatorname{SCIA}^{1} 01 *^{2}$ & $60,33^{*}$ & 23,14 & 60,05 & 75,40 & EVE & $\mathrm{T}_{0}$ \\
\hline SCIA $02 *$ & 80,67 & 21,13 & 66,77 & 98,76 & EVE & $\mathrm{T}_{0}$ \\
\hline $\operatorname{SCIA} 03 * *^{3}$ & 82,33 & 22,12 & 46,83 & 53,23 & EVE & $\mathrm{T}_{0}$ \\
\hline SCIA $04 *$ & $62,67 *$ & 21,53 & 77,47 & 57,63 & EVE & $\mathrm{T}_{0}$ \\
\hline SCIA $05 * *$ & 78,33 & 21,36 & 61,35 & 46,23 & DVA & $\mathrm{T}_{3}$ \\
\hline SCIA $06^{*}$ & 85,67 & 20,75 & 66,19 & 66,78 & EVE & $\mathrm{T}_{0}$ \\
\hline SCIA $07 *$ & 83,00 & 17,49 & 59,69 & 36,04 & DVA & $\mathrm{T}_{2}$ \\
\hline SCIA $08 * *$ & 78,33 & 19,62 & 78,47 & 58,67 & DVA & $\mathrm{T}_{0}$ \\
\hline SCIA $09 *$ & 82,00 & 19,10 & 51,67 & 36,88 & D VA & $\mathrm{T}_{2}$ \\
\hline SCIA $10 *$ & 74,33 & 19,38 & 74,48 & 50,95 & DVA & $\mathrm{T}_{2}$ \\
\hline SCIA $11 *$ & 81,00 & 17,63 & 78,72 & 44,94 & DVA & $\mathrm{T}_{2}$ \\
\hline SCIA $12 *$ & 72,33 & 17,64 & 63,01 & 37,73 & DVA & $\mathrm{T}_{0}$ \\
\hline SCIA $13 *$ & 69,67 & 17,40 & 80,64 & 65,39 & DVA & $\mathrm{T}_{0}$ \\
\hline SCIA $14 * *$ & 72,67 & 18,39 & 77,45 & 45,30 & DVA & $\mathrm{T}_{0}$ \\
\hline SCIA $15 *$ & 89,00 & 18,76 & 66,42 & 31,98 & DVA & $\mathrm{T}_{0}$ \\
\hline SCIA $16 *$ & 83,33 & 15,72 & 56,63 & 48,98 & DVA & $\mathrm{T}_{2}$ \\
\hline SCIA $17 *$ & $91,00^{*}$ & 18,67 & 53,78 & 38,63 & DVA & $\mathrm{T}_{3}$ \\
\hline SCIA $18 *$ & 72,33 & 21,22 & 66,28 & 60,63 & EVE & $\mathrm{T}_{0}$ \\
\hline SCIA $19 *$ & $93,00 *$ & 18,30 & 69,70 & 41,40 & EVE & $\mathrm{T}_{2}$ \\
\hline SCIA $20 *$ & 81,33 & 17,84 & 61,49 & 38,30 & EVE & $\mathrm{T}_{0}$ \\
\hline SCIA $21 *$ & 67,67 & 18,94 & 45,46 & 59,80 & EVE & $\mathrm{T}_{3}$ \\
\hline SCIA $22 *$ & 85,00 & 21,02 & 79,69 & 64,13 & EVE & $\mathrm{T}_{1}$ \\
\hline SCIA $23 *$ & 82,33 & 20,48 & 81,63 & 64,13 & EVE & $\mathrm{T}_{2}$ \\
\hline SCIA $24 *$ & $62,33^{*}$ & 20,22 & 65,36 & 64,10 & EVE & $\mathrm{T}_{1}$ \\
\hline SCIA $25^{*}$ & $90,33^{*}$ & 20,83 & 36,81 & 55,37 & EVE & $\mathrm{T}_{0}$ \\
\hline SCIA $26 *$ & 72,67 & 20,59 & 65,13 & 42,10 & DVA & $\mathrm{T}_{0}$ \\
\hline $\operatorname{SCIA} 27 * *$ & 72,33 & 18,89 & 50,26 & 29,13 & DVA & $\mathrm{T}_{2}$ \\
\hline SCIA $28 * *$ & 75,33 & 19,82 & 56,83 & 50,60 & DVA & $\mathrm{T}_{0}$ \\
\hline SCIA $29 *$ & 64,00 & 17,65 & 69,65 & 41,84 & DVA & $\mathrm{T}_{0}$ \\
\hline SCIA $30 *$ & 76,00 & 18,78 & 76,46 & 68,90 & EVE & $\mathrm{T}_{2}$ \\
\hline SCIA $31 * *$ & 74,67 & 17,81 & 79,92 & 60,33 & EVE & $\mathrm{T}_{0}$ \\
\hline $\operatorname{SCIA} 32 * *$ & $97,67 *$ & 33,49 & 69,67 & 55,18 & DVA & $\mathrm{T}_{2}$ \\
\hline SCIA $33 * *$ & 75,33 & 19,86 & 71,87 & 37,13 & DVA & $\mathrm{T}_{0}$ \\
\hline SCIA $34 * *$ & 72,33 & 17,33 & 56,99 & 60,04 & D VA & $\mathrm{T}_{2}$ \\
\hline SCIA $35 * *$ & 65,00 & 19,91 & 60,28 & 44,73 & D V A & $\mathrm{T}_{0}$ \\
\hline SCIA $36 * *$ & 71,33 & 20,05 & 73,45 & 59,92 & DVA & $\mathrm{T}_{2}$ \\
\hline $\operatorname{SCIA} 37 * *$ & 83,33 & 18,78 & 68,31 & 47,38 & D VA & $\mathrm{T}_{0}$ \\
\hline SCIA $38 *$ & 73,00 & 18,50 & 75,44 & 47,07 & DVA & $\mathrm{T}_{0}$ \\
\hline $\operatorname{SCIA} 39 * *$ & $62,33^{*}$ & 20,11 & 67,44 & 54,63 & D VA & $\mathrm{T}_{2}$ \\
\hline SCIA $40 * *$ & 67,33 & 20,61 & 58,08 & 29,15 & DVA & $\mathrm{T}_{0}$ \\
\hline SCIA $41 *$ & $62,33^{*}$ & 18,60 & 77,84 & 47,52 & DVA & $\mathrm{T}_{2}$ \\
\hline IAC $47^{4}$ & 76,67 & 18,31 & 71,48 & 53,75 & D V P & $\mathrm{T}_{0}$ \\
\hline
\end{tabular}

${ }^{1}$ Somaclone de IAC 47; ${ }^{2}$ Somaclones de ciclo precoce com duração de 110 dias; ${ }^{3}$ Somaclones de ciclo precoce com duração de 120 dias; ${ }^{4}$ Testemunha suscetível de ciclo médio com duração de 130 dias, não regenerada; ${ }^{5}$ Médias seguidas por um asterisco diferem significativamente da cultivar IAC 47 pelo teste de Tukey a $5 \%$ de probabilidade; ${ }^{6}$ Nenhum dos somaclones diferiu da cultivar IAC 47 pelo teste de Tukey a 5\% de probabilidade; EVE = Planta com folha ereta verde escura; DVA = Planta com folha decumbente verde-amarelo; $\mathrm{DVP}=$ Planta com folha decumbente verde-palha. $\mathrm{T}_{0}=$ grão igual a cultivar IAC 47, com apículo preto e sem arista; $\mathrm{T}_{1}=$ grão com arista vermelha; $\mathrm{T}_{2}=$ grão com apículo branco e sem arista; $\mathrm{T}_{3}=$ grão com arista preta. 
Progresso da brusone nas folhas e características agronômicas nas gerações...

lógicas como coloração de algum órgão da planta vêm sendo identificados no germoplasma, devido a ocorrência de variação na natureza ou através de tratamentos mutagênicos. Os genes para coloração de folha verde-escura e verde-amarela pertencem aos grupos de ligações 3 e 10, respectivamente (Khush \& Kinoshita, 1991). As variações dos somaclones para dois tipos distintos de plantas, diferentes da cultivar original IAC 47, podem ser consideradas como mutações genéticas e herdáveis como as que têm sido registradas em diversas culturas, inclusive arroz (Fukui, 1983, Cai et al., 1990). Comparados à cultivar IAC 47, todos os somaclones apresentaram ciclo precoce nas condições de campo, em Goiânia. Entre 41 somaclones, 15 e 26 apresentaram ciclos com duração de 120 e 110 dias, contra 130 dias da cultivar IAC 47. Quatro mutações para florescimento precoce foram obtidas em 12 progênies de arroz regeneradas a partir de calos de sementes (Fukui, 1983). Os somaclones apresentaram variação para três tipos diferentes de grãos, além do mesmo tipo de grão da cultivar IAC 47. Entre 41 somaclones, 22 apresentaram tipo de grão igual ao da cultivar IAC 47, dois mostraram o grão com arista vermelha, 14 apresentaram o grão com apículo branco e sem arista, e três mostraram o grão com arista preta. $\mathrm{O}$ estudo realizado com quatro cultivares de arroz com diferentes tipos de grãos mostraram que o comprimento e peso de grãos de somaclones foi reduzido comparado com os parentais (Zheng et al., 1989). Todos os somaclones apresentaram característica aromática nos testes realizados com a penúltima folha enquanto a cultivar IAC 47 não apresentou aroma. A mutação para esta característica derivada de uma cultivar não aromática é rara e inédita.

A severidade da brusone nas panículas dos 17 somaclones R variou de 24,7 a $74,5 \%$ (Tabela 4). Seis somaclones apresentáram significativamente maior severidade, enquanto os demais não diferiram da cultivar IAC 47. A correlação entre a brusone nas panículas nas gerações $\mathrm{R}_{5}$ e $\mathrm{R}_{6}$ foi positiva e significativa $(\mathrm{r}=0,58 ; \mathrm{P} \leq 0.05)$. Os somaclones não diferiram da cultivar IAC 47 quanto ao número de grãos totais por panícula, enquanto apresentaram diferenças na degranação. Entre 17 somaclones oito apresentaram degranação menor do que a cultivar IAC 47, indicando a superioridade dos mesmos. Os 17 somaclones apresentaram diferenças significativas em produtividade. Com exceção do somaclone SCIA02 que não diferiu da cultivar IAC 47 todos os outros foram inferiores (Tabela 4). O experimento foi prejudicado devido a ocorrência de veranico no florescimento. $\mathrm{Na}$ geração $\mathrm{R}_{7}$ os somaclones apresentaram diferenças significativas tanto para ASCPD como para taxa aparente de infecção (Tabela 2). Entre 41 somaclones, quatro e dois apresentaram ASCPD significativamente menor e maior, do que a cultivar IAC47, respectivamente. Levando em consideração a taxa aparente de infecção, 20 somaclones apresentaram valores de $r$ menores e quatro maiores do que a cultivar IAC 47. As correlações dos valores de ASCPD entre somaclones das gerações $\mathrm{R}_{6}$ e $\mathrm{R}_{7}(\mathrm{r}=0,69 ; \mathrm{P} \leq 0.01)$ e com relação à taxa aparente de infecção $(\mathrm{r}=0,60 ; \mathrm{P} \leq 0.01)$ foram significativas. Estes resultados indicaram a estabilidade quanto ao grau de

TABELA 4 - Número de grãos totais por panícula, degranação, severidade da brusone nas panículas e produtividade na geração $R_{6}$ de 17 somaclones da cultivar IAC 47, e peso de grãos de 100 panículas e produtividade de 13 somaclones $R_{7}$ da cultivar de arroz (Oryza sativa) IAC 47

\begin{tabular}{|c|c|c|c|c|c|c|}
\hline \multirow[b]{2}{*}{ Genótipo } & \multicolumn{4}{|c|}{ Geração $R_{6}(1996 / 97)$} & \multicolumn{2}{|c|}{ Geração $\quad R_{7}(1997 / 98)$} \\
\hline & $\begin{array}{c}\text { Severidade da } \\
\text { brusone nas } \\
\text { panículas }\end{array}$ & Degranação & $\begin{array}{c}\mathrm{N}^{\circ} \text { de grãos } \\
\text { totais por } \\
\text { panícula }\end{array}$ & $\begin{array}{l}\text { Produtividade } \\
\qquad(\mathrm{Kg} / \mathrm{ha})\end{array}$ & $\begin{array}{l}\text { Peso de grãos de } \\
100 \text { panículas (g) }\end{array}$ & $\begin{array}{l}\text { Produtividade } \\
\qquad(\mathrm{Kg} / \mathrm{ha})\end{array}$ \\
\hline SCIA 09 & $75,49 a^{2}$ & $1,40 \mathrm{bcd}$ & $75,91 \mathrm{ab}$ & $519,7 \mathrm{fg}$ & - & - \\
\hline SCIA 10 & $74,54 \mathrm{a}$ & $1,13 \mathrm{~d}$ & $79,21 \mathrm{ab}$ & $154,2 \mathrm{~g}$ & - & - \\
\hline SCIA 07 & $67,63 \mathrm{ab}$ & $1,93 \mathrm{abcd}$ & $88,83 \mathrm{ab}$ & $646,0 \mathrm{fg}$ & $104,7 b$ & $877,0 \mathrm{~cd}$ \\
\hline SCIA 11 & $65,61 \mathrm{abc}$ & $1,26 \mathrm{~cd}$ & $74,75 \mathrm{ab}$ & $738,6 \mathrm{efg}$ & - & - \\
\hline SCIA 15 & $64,84 \mathrm{abcd}$ & $1,60 \mathrm{bcd}$ & $86,62 \mathrm{ab}$ & $438,5 \mathrm{fg}$ & - & - \\
\hline SCIA 05 & $50,90 \mathrm{abcde}$ & $1,66 \mathrm{abcd}$ & $68,12 \mathrm{ab}$ & $907,3 \mathrm{def}$ & $143,7 \mathrm{ab}$ & $1079,0 \mathrm{bcd}$ \\
\hline SCIA 01 & $45,06 \mathrm{bcde}$ & $1,40 \mathrm{bcd}$ & $88,79 \mathrm{ab}$ & $1534,8 \mathrm{bcd}$ & $188,3 \mathrm{a}$ & $1510,0 \mathrm{ab}$ \\
\hline SCIA 16 & $44,09 \mathrm{bcde}$ & $2,20 a b c$ & $93,79 \mathrm{ab}$ & $1391,8 \mathrm{bcd}$ & $132,8 \mathrm{ab}$ & $1009,0 \mathrm{bcd}$ \\
\hline SCIA 17 & 45,46 bcde & $1,33 \mathrm{~cd}$ & $90,33 \mathrm{ab}$ & $385,5 \mathrm{fg}$ & $129,4 \mathrm{ab}$ & $679,6 \mathrm{~d}$ \\
\hline SCIA 03 & $37,10 \mathrm{e}$ & $1,73 \mathrm{abcd}$ & $61,96 b$ & $1378,0 \mathrm{bcde}$ & $158,9 \mathrm{ab}$ & $1432,0 \mathrm{abc}$ \\
\hline SCIA 13 & $37,36 \mathrm{de}$ & $1,93 \mathrm{abcd}$ & $89,25 \mathrm{ab}$ & $1631,7 b c$ & $131,9 \mathrm{ab}$ & $947,3 \mathrm{bcd}$ \\
\hline $\mathrm{IAC} 47^{1}$ & $45,10 \mathrm{bcde}$ & $2,66 \mathrm{a}$ & $60,17 b$ & $2368,1 \mathrm{a}$ & $162,4 \mathrm{ab}$ & $1072,0 \mathrm{bcd}$ \\
\hline SCIA 08 & $35,95 \mathrm{e}$ & $3,33 \mathrm{~cd}$ & $93,13 \mathrm{ab}$ & $990,3 \mathrm{cdef}$ & $163,2 \mathrm{ab}$ & $1190,0 \mathrm{abcd}$ \\
\hline SCIA 06 & $35,58 \mathrm{e}$ & $1,86 \mathrm{abcd}$ & $78,50 \mathrm{ab}$ & $1557,0 \mathrm{bcd}$ & $126,8 \mathrm{ab}$ & $1233,0 \mathrm{abcd}$ \\
\hline SCIA 04 & $34,84 \mathrm{e}$ & $2,40 \mathrm{ab}$ & $71,67 \mathrm{ab}$ & $1676,6 b$ & $149,5 \mathrm{ab}$ & $1433,0 \mathrm{abc}$ \\
\hline SCIA 12 & $26,25 \mathrm{e}$ & $1,46 \mathrm{bcd}$ & $84,25 a b$ & $973,1 \mathrm{def}$ & $120,7 \mathrm{ab}$ & $897,7 \mathrm{~cd}$ \\
\hline SCIA 14 & $27,71 \mathrm{e}$ & $2,00 \mathrm{abcd}$ & $102,46 a$ & $1522,6 \mathrm{bcd}$ & $113,0 \mathrm{ab}$ & $799,3 \mathrm{~d}$ \\
\hline SCIA 02 & $24,67 \mathrm{e}$ & $1,46 \mathrm{bcd}$ & $85,29 \mathrm{ab}$ & $2588,2 \mathrm{a}$ & $180,0 \mathrm{ab}$ & $1774,0 \mathrm{a}$ \\
\hline
\end{tabular}

${ }^{1}$ Testemunha suscetível, não regenerada.

${ }^{2}$ Médias seguidas da mesma letra não diferem pelo teste de Tukey a 5\% de probabilidade. 
resistência da brusone nas folhas nas duas gerações.

$\mathrm{O}$ experimento de campo, realizado para verificar o potencial de produtividade de 13 somaclones $R_{7}$ mostrou diferenças significativas no peso de grãos de 100 panículas e produtividade (Tabela 4). Com exceção de um, os somaclones não diferiram da cultivar IAC 47 quanto ao peso de grãos por 100 panículas. A produtividade do SCIA02 (1774 kg/ha) foi superior a da cultivar IAC $47 \mathrm{com} 1072 \mathrm{~kg} / \mathrm{ha}$. O mesmo somaclone sobressaiu-se nas gerações $R_{6}$ e $R_{7}$.

Os dois somaclones SCIA02 e SCIA06 apresentaram progresso lento da brusone nas folhas, precocidade com duração do ciclo de 110 dias, alta produtividade quando comparados à cultivar IAC 47, além de tipo de planta com folha ereta verde e aroma. Estes somaclones têm grande valor para utilização como doadores de resistência visando melhoramento de arroz de terras altas. Os mesmos somaclones apresentaram maior grau de resistência parcial sensu Parlevliet \& Omeren (1975), nos testes realizados na geração $\mathrm{R}_{4}$ com uma raça virulenta em condições controladas de casa de vegetação (Araújo et al., 1997).

Observou-se variação para algumas características agronômicas importantes, além da brusone, nos somaclones derivados da cultivar IAC 47, confirmando diversos outros relatos em arroz (Fukui, 1983; Mandal et al., 1999). Nas plantas de arroz regeneradas, $75 \%$ apresentaram mutações morfológicas (Oono, 1978). Entretanto a freqüência de alteração em altura, fertilidade e outras características tem sido variável em diferentes cultivares (Zhuravlev \& Zmeeva, 1996). Neste trabalho a freqüência de características desejáveis de somaclones derivados da cultivar IAC47 pode ser considerada alta. A fonte principal de variação foi a obtenção de plantas regeneradas a partir de calos de panículas imaturas. Alguns dos somaclones têm valor para o melhoramento genético, com precocidade e aroma do grão. A variação somaclonal, a partir de cultivares comerciais de arroz pode ser utilizada para recuperar, em alta freqüência, características agronômicas que permanecem estáveis ao longo das gerações.

\section{AGRADECIMENTOS}

Ao Dr. Francisco José P. Zimmermann pelo auxílio na análise estatística, ao Pedro Maurício Machado pela assistência na realização dos experimentos de campo e ao $\mathrm{CNPq}$ por ter financiado parcialmente este estudo.

\section{REFERÊNCIAS BIBLIOGRÁFICAS}

AHN, S.W. The slow blasting resistance. Proceedings, Symposium on Rice Resistance to Blast, Montpellier, França. 1981. pp. .343-370.

ARAÚJO, L.G., PRABHU, A.S. \& FREIRE, A.B. Development of blast resistant somaclones of the upland rice cultivar Araguaia. Pesquisa Agropecuária Brasileira 35:357-367. 2000.

ARAÚJO, L.G., PRABHU, A.S. \& FREIRE, A.B. Variação somaclonal na cultivar de arroz IAC-47 para resistência à brusone. Fitopatologia Brasileira 22:125-130. 1997.

BASTIAANS, L., RABBINGE, R. \& ZADOKS, J.C. Understanding and modeling leaf blast effects on crop physiology and yield. In: Zeigler, R.S., Leong, S.A. \& Teng, P.S. (Eds.). Rice blast disease. Wallingford. CAB. 1994. pp. 357-380.

CAI, T., EJETA, G., AXTELL, J.D. \& BUTLER, L.G. Somaclonal variation in high tannin sorghums. Theoretical and Applied Genetics 79:737-747. 1990.

CHAUHAN, R.S., SINGH, B.M., CHAHOTA, R.K. \& DEVELASH, R.K. Generation of indica rice regenerants for resistance to leaf and neck blast. Rice Biotechnology Quarterly 26:28-29. 1996.

DUVAL, C.M., CALDAS, L.S. \& RESENDE, R. de O. Aplicações da cultura de tecidos na fitopatologia. In: Torres, A.C., Caldas, L.S. \& Buso, J.A. (Eds.) Cultura de tecidos e transformação genética de plantas. Brasília. Embrapa-SPI. 1998. pp.45-68.

FUKUI, K. Sequential occurrence of mutation in a growing rice callus. Theoretical and Applied Genetics 65:225230. 1983.

KHUSH, G.S. \& KINOSHITA, T. Rice karyotype, markers genes, and linkage groups. In: Khush, G.S., Toenniessen, G.H. (Eds.). Rice Biotechnology. Manila. 1996. pp.83108.

MANDAL, A.B. \& BANDYOPADHYAY, A.K. Altered grain quality traits in Pokkali somaclones. Rice Biotechnology Quarterly 27:21-22. 1996.

MANDAL, A.B., PRAMANIK, S.C., CHOWDHURY, B. \& BANDYOPAD n indigenous cultivar Pokkali. Rice Biotechnology Quarterly 39:9-10. 1999.

NOTTEGHEM, J.L. Cooperative experiment on horizontal resistance to rice blast. In: INTERNATIONAL RICE RESEARCH INSTITUTE (Los Baños, Filipinas). Blast and Upland Rice: Report and Recommendations From the Meeting for International Collaboration in Upland Rice Improvement. Los Baños. 1981. pp.43-51.

OONO, K. High frequency mutations in rice plants regenerated from seed callus. Proceedings, Fourth International Congress Plant Tissue Cell Culture, Calagary, Canada. 1978. p.52.

PARLEVLIET, J.E. \& OMMEREN, V.A. Partial resistance of barley to leaf rust Puccinia hordei. II. Relationship between field trials, microplot tests and latent period. Euphytica 24:223-303. 1975.

PRABHU, A.S. \& BEDENDO, I.P. Avaliação de resistência horizontal à brusone em cultivares de arroz. Fitopatologia Brasileira 16:34-39. 1991.

PRABHU, A.S. \& FERREIRA, R.P. Avaliação e seleção no melhoramento de arroz irrigado visando resistência à brusone e mancha parda. In: Reunión Sobre Mejoramiento de Arroz en el Cono Sur, Goiânia, GO. 1989. pp.75-85.

PRABHU, A.S., FILIPPI, M.C. \& ZIMMERMMANN, F.J.P. Genetic control of blast in relation to nitrogen fertilization in upland rice. Pesquisa Agropecuária 
Progresso da brusone nas folhas e características agronômicas nas gerações...

Brasileira 31:339-347. 1996.

SHANER, G. \& FINNEY, R.E. The effect of nitrogen fertilization on the expression of slow-mildewing resistance in knox wheat. Phytopathology 67:1051-1056. 1977.

SNEDECOR, G.W. \& COCHRAN, W.G. Statistical Methods. $6^{\text {nd }}$ ed. Ames. Iowa State University Press. 1978.

SOOD, B.C. \& SIDDIQ, E.A. A rapid technique for scent determination in rice. Indian Journal of Genetics and Plant Breeding 38:268-271. 1978.

VANDERPLANK, J.E. Plant Diseases: Epidemics and Control. New York. Academic Press. 1963.
YURKOVA, G.N., LEVENKO, B.A. \& NOVOZHIILOV, P.V. Plant regeneration in wheat tissue culture. Biochemie und Physiologie der Pflanzen 177:337-344. 1982.

ZHENG, K.L., ZHAN, Z.M., WANG, G.L. \& LUO, Y.K. Somatic cell culture of rice cultures with different grain types. Somaclonal variation in some grain and quality characters. Plant Cell Tissue Organ Culture 18:201-208. 1989.

ZHURAVLEV, Y.N. \& ZMEEVA, V.N. Gameto and somaclonal variations in rice cultivars of Russian far East. In: INTERNATIONAL RICE RESEARCH INSTITUTE. Rice Genetics III. Manila. 1996. pp.505-510. 